\title{
"A TEORIA TEM CONSEQUÊNCIAS": INDAGAÇÕES SOBRE O CONHECIMENTO NO CAMPO DA EDUCAÇÃO
}

\author{
Maria Célia Marcondes de Moraes*
}

A certeza da prática imediata é comprada ao preço do ceticismo em relação a tudo que ultrapassa seu estreito horizonte. (Mário Duayer)

\begin{abstract}
RESUMO: A proposta do artigo é levantar a denúncia de que o conhecimento e a ciência estão sob ameaça, notadamente as ciências humanas e sociais, e formular a crítica de que o atual contexto de ceticismo epistemológico e de relativismo ontológico compromete a capacidade de as ciências superarem suas próprias antinomias, tanto no plano explanatório como no do enfrentamento prático de seus problemas. $\mathrm{O}$ artigo retoma a frase "a teoria tem consequências" e argumenta que a teoria pode acentuar o ceticismo generalizado sobre o conhecimento, a verdade e a justiça, tornando-os sem sentido e introduzindo uma boa dose de irracionalismo e niilismo. Em seu lado positivo, a teoria pode oferecer as bases racionais e críticas para desnudar a lógica do discurso que, ao mesmo tempo em que afirma a centralidade da educação, elabora a pragmática construção de epistemologias da prática condizentes com os paradigmas que referenciam pesquisas, reformas, planos e propostas para a educação brasileira e latino-americana. A base teórica do texto é o realismo crítico de Lukács e Bhaskar.
\end{abstract}

Palavras-chave: Conhecimento. Epistemologia da prática. Empirismo. Realismo crítico. Ontologia.

* In Memoriam.

Educ. Soc., Campinas, vol. 30, n. 107, p. 585-607, maio/ago. 2009

Disponível em <http://www.cedes.unicamp.br> 
"A teoria tem consequências": indagaçôes sobre o conhecimento no campo da educação

\author{
“Theory does haVe CONSEQUences": \\ QUESTIONING KNOWLEDGE IN THE FIELD OF EDUCATION
}

\begin{abstract}
This paper explores the denunciation that knowledge and science, more particularly human and social sciences, are at risk. It criticizes the context of epistemological scepticism and ontological relativism that strongly affects sciences' capacity to overcome their own antinomies either on an explanatory level or when practically confronted to their own problems. It recalls the sentence "theory does have consequences" and argues that theory can increase the generalized scepticism about knowledge, truth, and justice by making them sound meaningless, thus opening the door to a great measure of irrationalism and nihilism. Yet, the positive side of theory may offer rational and critical bases to unveil the logic of a discourse that, at the same time, affirms education centrality and proposes the pragmatic construction of practice epistemologies in keeping with the emergent paradigms that are references for research, reforms, plans and proposals for Brazilian and Latin-American education. Theoretically, this text is based on Lukács and Bhaskar's critical realism.
\end{abstract}

Key words: Knowledge. Epistemology of practice. Empiricism. Critical realism. Ontology.

\title{
Introdução
}

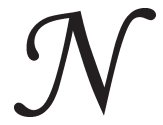

ão tenho a intenção, nesse artigo, de fazer uma exposição acadêmica stricto sensu sobre aspectos epistemológicos das ciências contemporâneas ou sobre as novas perspectivas teóricas e metodológicas, os novos objetos e abordagens que testemunhamos nesse campo. Ao contrário, minha proposta é levantar uma denúncia e formular uma crítica. A denúncia: o conhecimento e a ciência estão sob ameaça, notadamente as ciências humanas e sociais. A crítica: o contexto de ceticismo epistemológico e de relativismo ontológico que hoje nos cerca compromete acentuadamente a capacidade de as ciências superarem suas próprias antinomias, tanto no plano explanatório como no do enfrentamento prático de seus problemas.

Em 1979, o historiador marxista inglês E. P. Thompson, em um debate em Oxford, afirmou com grande paixão e em defesa de seu livro $A$ miséria da teoria: um planetário de erros (1978): “a teoria tem consequências!". A frase foi retomada anos mais tarde pelo filósofo 
gaulês Christopher Norris (1996, p. Ix), que detalhou as consequências negativas e positivas da teoria. Por um lado, a teoria pode acentuar o ceticismo generalizado sobre o conhecimento, a verdade e a justiça, tornando-os sem sentido e, em decorrência, introduzir uma boa dose de irracionalismo, cinismo e niilismo - como é o caso das várias correntes que compõem a agenda pós-moderna. Contudo, em seu lado positivo, a teoria pode nos oferecer as bases - racionais e críticas - para rejeitar muito do que a nova direita nos apresenta como sabedoria política realista. No caso da educação, ela pode nos ajudar a desnudar a lógica do discurso que, ao mesmo tempo em que afirma a sua centralidade, elabora a pragmática construção de um novo vocabulário que ressignifica conceitos, categorias e termos, de modo a torná-los condizentes com os emergentes paradigmas que referenciam as pesquisas, reformas, planos e propostas para a educação brasileira e latino-americana.

Este é o tema geral de minha exposição e vou dividi-la em duas partes. Na primeira, detalho a denúncia e a crítica às quais me referi. Meu argumento é o de que, neste momento crucial para a compreensão das questôes sociais, em que o capitalismo produz forte degradação da vida humana, verifica-se certa tendência de supressão do aprofundamento teórico nas pesquisas na área da educação, com gravíssimas implicações políticas, éticas, além, naturalmente, das epistemológicas. Esta tendência tem dupla vertente: em uma delas verifica-se a crescente influência do realismo empírico (Bhaskar, 1997, 1979, 1986 e 1993), movimento que prioriza a eficiência e a construção de um terreno consensual que reduz o horizonte da pesquisa e da formação docente ao saber tácito, à prática instrumental, plasmando-se o processo cognitivo no interior de limites que se definem pela formatação da capacidade adaptativa dos indivíduos e pela narrativa descritiva da experiência (Moraes, 2001, 2003). Por ser assim, assegura Duayer (2006, p. 124), o realismo empírico "aparenta neutralidade ontológica e, nessa fictícia recusa a falar do mundo como ele é, toma-o tal como ele se apresenta de imediato, atitude que contorna a 'contingência das questôes existenciais' e reforça dogmaticamente o status quo conceitual, epistêmico e social."

$\mathrm{Na}$ outra, observa-se um aspecto ainda mais grave, o embaralhamento entre ceticismo epistemológico e relativismo ontológico, de acentuado perfil pós-moderno. Nossos conhecimentos são relativos, dizem, porque são sociais, históricos, contextualizados, conjunturais, culturais etc., e desse caráter transitório e relativo infere-se que nosso 
"A teoria tem consequências": indagaçôes sobre o conhecimento no campo da educação

conhecimento não pode ser objetivo, será sempre um ponto de vista individual, de um grupo, de uma cultura. Ou seja, por atestar que idéias, teorias etc. opostas não podem ser objetivamente comparadas, conclui-se a impossibilidade da crítica, de cotejar as várias correntes de pensamento, pois mesmo reconhecendo o real, conclui-se que não se pode ter um conhecimento objetivo a seu respeito.

Nessa perspectiva cética e relativista, o mundo social é esvaziado de qualquer dimensão estrutural duradoura que apenas o esforço teórico pode alcançar. Por conseguinte, a teoria que se constrói, nivelada em seu conjunto por indiferenciado relativismo, restringe-se a descrever e, quando muito, a nomear as formas fenomênicas do cotidiano. Tenho escrito sobre este tema nos últimos anos e nesse artigo retomo algumas idéias que amadureci nesse percurso (Moraes, 1996, 2001, 2003, 2003a, 2004; Duayer \& Moraes, 1988).

$\mathrm{Na}$ segunda parte de minha exposição, deter-me-ei sobre o aspecto positivo das consequências da teoria e o conhecimento, com base no realismo crítico de Lukács e Bhaskar e nas discussões a este respeito desenvolvidas, entre outros, por Duayer (2004) e Medeiros (2004).

\section{A adequação empírica e a utilidade instrumental da teoria}

Desde os anos que se seguiram à Segunda Guerra Mundial e, em particular, a partir do final da década de 1960, vimos percebendo os ruídos da contra-revolução capitalista, a qual introduziu fortes mudanças sociais, colocou indagações e exigiu respostas que não mais encontravam respaldo nos referentes tradicionais do conhecimento. Foram os tempos desestabilizadores da reestruturação socioeconômica em escala planetária e da internacionalização do mercado sobre o traçado econômico do mundo contemporâneo. Tal estado de coisas teve efeitos ao mesmo tempo extensos e profundos sobre as várias práticas sociais e, de modo particular, sobre a educação (Moraes, 2004).

De fato, o elevado grau de competitividade ampliou a demanda por conhecimentos e informações e, em decorrência, a educação foi eleita como estratégia para fazer face à velocidade das mudanças. A escola tradicional, a educação formal, as antigas referências educacionais tornaram-se obsoletas. Impôs-se a demanda por uma nova pedagogia, um projeto educativo de outra natureza, pois, pensou-se, não basta 
apenas educar, é preciso assegurar o desenvolvimento de "competências", valor agregado a um processo que, todavia, não é o mesmo para todos. Para alguns, exige níveis sempre mais altos de aprendizagem, posto que certas "competências" repousam no domínio teórico-metodológico que a experiência empírica, por si só, é incapaz de garantir. Para a maioria, porém, bastam as "competências" - no sentido genérico que o termo adquiriu hoje em dia, o de saber tácito - que permitem a sobrevivência nas franjas do núcleo duro de um mercado de trabalho fragmentado, com exigências cada vez mais sofisticadas e formidáveis níveis de exclusão (Moraes, 2001, 2004).

Percebem-se, assim, as rápidas mudanças em tecnologia no "chão da escola", locais de trabalho e residências, afetando o modo de aprendizagem dos estudantes e as habilidades que eles adquirem. Procurase, a qualquer custo e de qualquer forma, adaptar alunos e docentes à nova realidade; cresce a exigência pública quanto à avaliação dos sistemas educacionais, de administradores e docentes; reduz-se o financiamento da educação nos âmbitos local, estadual e nacional com impactos sobre salários e recursos educacionais de todo tipo; aumenta a demanda pela educação à distância e continuada; percebem-se pressões psicológicas e físicas em diferentes modos de aprendizagem. Não obstante, o recorrente discurso que proclama o caráter salvacionista da educação diminui a compreensão e o interesse por parte dos pais, das empresas e do governo em apoiar necessidades e mudanças educacionais. Marginaliza-se o professor em sala de aula, justamente aquele de quem dependemos para a transmissão e socialização de conhecimentos, mas a quem se atribui, em grande medida, a culpa pelo "fracasso" escolar. Crescem a diversidade e a complexidade na sala de aula e a necessidade de atender e acomodar as questôes que estas levantam.

Além dos impactos decorrentes da reestruturação socioeconômica, aqueles foram tempos, também, em que imperavam os preceitos da agenda pós-moderna, a época cética e pragmática dos textos e das interpretações que não podem mais expressar ou, até mesmo, se aproximar da realidade, pois se constituem em simples relatos ou narrativas que, presas às injunções de uma cultura, acabam por apoiar-se no contingente e na prática imediata (Moraes, 1996, 2001, 2004a). Nessas circunstâncias, as teorias nos são apresentadas como meros discursos a respeito do mundo - desse ponto de vista, um mundo efetivamente insondável -, formas de expressão desprovidas de qualquer 
"A teoria tem consequências": indagaçôes sobre o conhecimento no campo da educação

estatuto ontológico privilegiado ou, mais diretamente, como construtos, jogos de linguagem incomensuráveis e sem sujeitos.

Os preceitos de tal agenda, ainda que sob múltiplas roupagens, permanecem presentes nas pesquisas da área de educação nos dias de hoje e carregam seus três princípios básicos: 1) o princípio da naturalização do capital, que significa o entendimento de que as estruturas sociais existentes são efetivamente imutáveis; 2) o princípio do atomismo social, que caracteriza a sociedade como um objeto constituído por uma simples agregação de indivíduos, e 3) o princípio da afirmação abstrata de valores emancipatórios, que se refere à descrição dos valores como entidades absolutamente subjetivas, descoladas da práxis social (Medeiros, 2004, f. 31) Os três princípios associam-se aqui à idéia de desintegração do espaço público, do fetichismo da diversidade, da compreensão de que o poder e a opressão estão pulverizados em todo e qualquer lugar. Daí resulta a impossibilidade de estabelecer uma base de resistência que possibilite o enfrentamento da realidade efetiva (Moraes \& Duayer, 1988).

Tais acontecimentos preocupam educadores e os levam a refletir sobre os processos educacionais, as ciências e, até mesmo, sobre a própria possibilidade do conhecimento objetivo. Interessante notar que esse processo ocorre em um cenário no qual se difunde a informação e o conhecimento como paradigmas do padrão civilizatório contemporâneo. Mas é preciso desnudar o tipo de conhecimento em tela - e aqui retomo minha denúncia e minha crítica: um conhecimento empobrecido, reduzido a um dos múltiplos "saberes" que germinam com rapidez na academia e fora dela, no qual se rompe a íntima cumplicidade e reciprocidade entre teoria e prática no processo cognitivo, ganhando esta última absoluta prerrogativa (Moraes, 2001, 2003, 2004a).

Tomando a educação como exemplo, com frequência o fascínio do modo de operar do ato educativo no cotidiano escolar transforma essa experiência em limite da inteligibilidade. Nas pesquisas e em eventos da área, são comuns uma supervalorização da subjetividade do trabalho docente e as célebres "histórias ou relatos do cotidiano escolar", narrativas subjetivas e/ou descritivas, quase sempre prescritivas, eivadas de "dever-ser".

Interessa-nos, aqui, colocar em questão este conjunto de interpretaçóes que, por sua incapacidade constitutiva de compreender os 
profundos desajustes sociais e educacionais como resultado das próprias relaçóes sociais, acaba por atribuir a sua existência à natureza, ao Estado, à perversão da vontade privada, à incompetência do professor, às precárias condições da escola e assim por diante. Aliás, é este o contexto da crítica ao perfil tradicional do professor "esclarecido" o que possui uma visão global do saber, conhece seus fundamentos, possui critérios epistemológicos, exerce sua racionalidade crítica e, sobretudo, está investido do direito de ensinar e afirmar a escola como efetivação prática dessa racionalidade (Moraes, 2004a).

É nesse campo, também, que imperam as chamadas "epistemologias da prática” e outras do mesmo naipe referentes à formação docente. Tardif (2000, p. 10), por exemplo, recomenda uma "epistemologia da prática profissional" que, em oposição ao saber acadêmico, teórico, científico, introduz "o estudo do conjunto dos saberes utilizados realmente pelos professores em seu espaço de trabalho cotidiano para desempenhar sua tarefa", pois é daí, da própria prática, que devem ser extraídos os fundamentos epistemológicos do ofício do professor. Outro exemplo é o de Schön $(1997 ; 1998)$, com grande aceitação na área da educação, que supervaloriza o saber tácito, o conhecimento adquirido por meio das experiências, e põe em segundo plano o conhecimento escolar, tanto no que diz respeito ao processo de ensinoaprendizagem na relação professor-aluno, quanto na própria formação dos docentes. Ou seja, o saber escolar iguala-se ao saber cotidiano e valorizam-se as formas de percepção e pensamento próprias da prática cotidiana. Perrenoud (1999, p. 54), por sua vez, recomenda que a formação docente seja submetida a uma "pequena revolução cultural", com uma inversão de prioridades: da "lógica do ensino" para a "lógica do treinamento". Ressalte-se, ainda, a concepção hoje hegemônica de formação docente em Portugal, denominada "sócio-construtivista", na qual a prática é definida como "o significado construído na experiência de vida cotidiana, no cotidiano do exercício da profissão. Logo, a prática profissionalizante docente é uma experiência de construção de significado ao nível das competências de ação" (Oliveira-Formosinho, 2002, p. 64, apud Raupp, 2007).

Lembro, ademais, que é este o contexto da "construção de um outro tipo de profissional da educação, cuja legitimidade social não repousa mais nos conhecimentos que possui ou transmite, mas nas competências que constrói e que o habilita para o convívio com situações 
"A teoria tem consequências": indagações sobre o conhecimento no campo da educação

cada vez mais complexas e incertas" (Campos, 2002, p. 86). É o "professor profissional”, informado pela epistemologia da prática, competente para responder às questões de suas tarefas cotidianas. As competências desse professor, assinala Campos (2002), são baseadas nas concepções construtivistas, nos métodos ativos de aprendizagem, bem como na psicologia cognitiva. Ademais, elas sinalizam a emergência de concepçôes mais individualizadas e subjetivas dos percursos de aprendizagem, a retomada do "aprender a aprender", vinculado às condições atuais de adaptabilidade.

O conhecimento, dessa forma, é hierarquizado por sua utilidade (Moraes, 2004a) e identificado com o vocabulário da prática. Tal atitude, embora periférica, é extremamente eficaz neste nível, devido a sua acentuada operacionalidade e as teorias construídas sobre esta base justificam-se por sua adequação empírica e por sua utilidade instrumental. Concepções equivocadas podem perfeitamente se amoldar à manipulação instrumental de objetos e estruturas da realidade, permitindo que os seres humanos respondam às demandas da vida cotidiana ou, se quisermos, do chão da escola.

Para Bhaskar (1993, p. 4), propostas dessa natureza supõem a ausência de três dimensôes do conhecimento. A ausência de diferenciação significa homogeneizar a realidade pela experiência. A ausência de profundidade representa a limitação do real ao nível do imediato, restringindo sua compreensão ao meramente empírico. Se tudo é aparência, não há profundidade. A ausência de um futuro aberto indica a impossibilidade de emergência do novo. Se a história acabou, acabou também a intervenção humana, acabou o mundo.

Um efeito notório da ausência dessas três dimensões - ao lado do da "desintelectualização" do professor (Shiroma, 2003, p. 74) - é a despolitização da formação docente em nome de um novo "modelo técnico". Essa racionalidade sugere que a prática docente é "neutra" por se voltar quase que exclusivamente ao limite intraescolar. Dispensa, assim, o conhecimento como campo de compreensão da inteligibilidade do mundo e desobriga, portanto, o pensamento de considerar as determinações desse mesmo mundo. Despolitiza a formação e a própria prática, pois, mesmo aceitando a idéia de conflito, o reduz à imediaticidade das diversidades individuais ou, no máximo, das de grupos. No afã de sobrevalorizar a experiência cotidiana dos professores em seu 
espaço de trabalho, as imprecisões e incongruências peculiares a tal epistemologia da prática os tolhem em sua capacidade de capturar as relaçōes funcionais dos fenômenos empíricos. Os fragilizam frente à complexidade da realidade social que envolve a educação e a trama de desafios da sala de aula. Nessas circunstâncias, o professor, ou qualquer sujeito portador dessa proposta, "embora capaz de reconhecer a precariedade do processo educativo, ou mesmo do caráter sórdido das relações sociais prevalecentes em escala planetária, de sonhar e até vislumbrar a possibilidade de uma vida melhor, revela-se impotente para intervir e atuar no mundo real" (Moraes \& Duayer, 1998, p. 106-107).

Está fora de questão qualquer proposta de desqualificar a experiência dos docentes em sala de aula, o desenvolvimento de seu saber tácito, o aprimoramento de sua percepção da prática cotidiana. É inegável a importância do conhecimento detalhado do plano do fenômeno empírico. Como se sabe, as experiências com alguma possibilidade científica dependem da atividade experimental ou sensorial, quer dizer, têm como alicerce o papel do seres humanos, seja como agentes causais, seja como aqueles que percebem. Trata-se, apenas, de sublinhar a radical insuficiência desse nível em termos de apreensão do complexo caráter intransitivo dos fenômenos do mundo.

É com base nos fenômenos empíricos abstratos que a pesquisa pode chegar a compreender sua essência conceitual (Goldmann, 1979; Moraes, 2000), pois é nos movimentos mais simples da vida cotidiana que se situa o início do processo de compreensão do ser social em seu sentido ontológico (Moraes \& Müller, 2003). No entanto, no dia-adia, a complexidade da realidade social apresenta-se em termos muito deformados, pois como lembra Marx (1982, p. 41), em sua vida diária o ser humano é movido por suas necessidades de sobrevivência "do estômago e da fantasia”. Ou seja, se aquilo que caracteriza o empírico é o subjetivo, o que é capturado pelas percepções do sujeito, então o entendimento do mundo limita-se ao que ele percebe. Dessa forma, "a noção contida no conceito de mundo empírico é antropocêntrica, pois postula que o mundo é o que os seres humanos podem experimentar. Nessa perspectiva, não se reconhece que para a experiência poder ser significativa para ciência é preciso que se reconheça a atividade social que a antecede" (Ávila, 2007, p. 20). 
"A teoria tem consequências": indagaçôes sobre o conhecimento no campo da educação

Por isso, informa Lukács (1979, p. 32), é necessário que o ponto de partida do conhecimento se constitua em uma abstração correta, que em sua estrutura interna já possua características da pesquisa científica. Filosofia e ciência originam-se na vida cotidiana, desenvolvem-se como instâncias autônomas para, finalmente, retornarem à práxis imediata e informá-la com novas ou melhores concepçôes. O aprofundamento teórico possibilitado pelas formas mais sofisticadas de conhecimento permite um alargamento do escopo da práxis humana, fazendo com que o que se apresentava como um paradoxo à experiência imediata passe a ser compreendido como verdade científica. Marx (1865) assinala que é um paradoxo que a "terra se mova em volta do sol e que a água seja constituída por dois gases altamente inflamáveis. A verdade científica é sempre um paradoxo do ponto de vista da experiência imediata que alcança apenas a mistificada aparência das coisas".

Recorro a idéias de Bhaskar $(1986,1993,1997)$ para concluir esta seção: o mundo é uma totalidade estruturada, diferençada e em mudança e, por conseguinte, não pode, de forma alguma, ser reduzido aos limites do realismo empírico. Só podemos compreender o mundo social - e, portanto, intervir sobre ele e não meramente responder a seus imperativos - se identificarmos as estruturas em funcionamento que geram os eventos, as aparências ou os discursos. Como tais estruturas não se mostram espontaneamente no que é observado, elas só podem ser identificadas mediante o trabalho teórico e prático das ciências sociais, ou, nas palavras de Bhaskar (1997, p. 31), "A experiência cientificamente significante normalmente depende da atividade experimental, bem como da percepção sensorial; ou seja, depende do papel dos homens seja como agentes causais, seja como perceptores", não importando se os agentes envolvidos estejam ou não cientes dessas relações. É pelo fato de serem potencialmente capazes de iluminar tais relações que as ciências sociais podem vir a ser tornar emancipátórias.

A teoria e sua capacidade emancipatória

Chego à segunda parte desse artigo, na qual proponho, em primeiro lugar, discutir o conhecimento do ponto de vista da ontologia e, em segundo, sublinhar o caráter positivo das consequências da teoria daí decorrente que pode contribuir para a construção de uma 
contra-hegemonia ao quadro que acabo de apresentar. Refiro-me à ontologia, mais especificamente ao realismo crítico de Lukács e Bhaskar.

Após alguns séculos ocupando um lugar secundário no âmbito da filosofia, uma vez que cedera seu lugar em cena para a gnosiologia e para a epistemologia, a ontologia, no século Xx, retomou seu importante lugar nas discussões filosóficas. A questão sobre "o que é" a questão do ser - tornou-se cada vez mais presente quando se pergunta sobre "o como" conhecer. Tenha-se ou não consciência desse fato, a resposta do pesquisador à questão "o que é a realidade?" fundamenta sua compreensão do que são o conhecimento e a ciência e, dessa forma, determina seus pressupostos e direciona seu processo de pesquisa (Moraes, 2000).

Creio que aqui cabe perfeitamente a instigante questão colocada por Bhaskar (1993) sobre a relação entre atividade humana e sociedade. A realidade social é compreendida por ele como um conjunto articulado de estruturas relativamente duradouras e independentes do agir humano; as estruturas são históricas, interdependentes e interconectadas, por serem uma totalidade complexa de relações sujeita à modificação tanto em seus componentes, quanto em suas interrelações, influenciando as operações umas das outras. Os vários momentos dessa totalidade podem ser, por certo, assimetricamente ponderados, dispondo de força causal diferenciada.

Esta interferência mútua, assevera Callinicos (2006), significa que não há uma resposta a priori que assegure que uma determinação irá de fato operar, pois outras determinações podem interferir, dificultando, distorcendo ou mesmo impedindo o mecanismo em questão de produzir os efeitos que produziria se não houvesse tal interferência. Por essa razão, na práxis social, o ser humano jamais tem condições de controlar todos os desdobramentos de suas ações; o resultado final pode ser até mesmo contrário às intenções originais, pois estas sempre dependem de fatores atuantes em determinadas circunstâncias (históricas, econômicas, naturais, culturais etc.) que prevalecem sobre as intenções individuais. Não é de estranhar, nesse contexto, que os resultados da práxis social e da educativa, em particular, sejam incertos e imprevisíveis. Daí o caráter explanatório e não-preditivo das ciências sociais e humanas. ${ }^{1}$ 
"A teoria tem consequências": indagaçôes sobre o conhecimento no campo da educação

De acordo com Bhaskar, os seres humanos não fazem as estruturas sociais, uma vez que tais estruturas preexistem a eles. Todavia, por outro lado, as estruturas sociais, por serem objetos sociais, não são independentes da atividade humana. A sociedade, portanto, fornece as condiçỗes necessárias para a ação humana intencional e esta é uma condição necessária para a sociedade. "A sociedade encontra-se em relação com os indivíduos, portanto, como algo que eles nunca fazem, mas que existe somente em virtude de sua atividade" (Bhaskar, 1979, p. 42).

Dito de outro modo: toda ação humana singular pressupõe determinadas condições. Por exemplo, "todo ato de fala pressupõe a existência da linguagem, todo cheque pressupõe a existência do sistema bancário, toda greve pressupôe a existência do sistema de classes sociais, toda mercadoria pressupóe a existência do mercado, todo pecado pressupõe a existência da religião, e assim por diante" (Medeiros, 2004 , f. 15). Tais estruturas sociais antecedem a própria atividade humana, no sentido de que os seres humanos se deparam com elas "já prontas ao nascer” (Bhaskar, 1979, p. 42-43). Em outros termos, a existência de estruturas sociais é anterior ao indivíduo, o que claramente "implica a sua existência fora dele mesmo (...). Desta forma, se o social não pode ser reduzido ao (e não é o produto do) indivíduo, fica igualmente claro que a sociedade é uma condição necessária para todo e qualquer ato humano intencional."

Bhaskar (1979, p. 43) fala do caráter dual da sociedade e da práxis humana de modo que a sociedade é, ao mesmo tempo, condição material previamente presente, mas também resultado continuamente reproduzido pela atividade humana. Em outras palavras,

(...) a sociedade afigura-se tanto como uma condição (causa material) sempre presente, como também um resultado continuamente reproduzido da ação humana. E a práxis constitui-se tanto em trabalho, ou seja, produção consciente, como também em reprodução (normalmente inconsciente) das condições de produção, que é a sociedade. Pode-se referir à dualidade da sociedade como uma dualidade de estrutura, e à última como sendo a dualidade da práxis.

Repetindo, então: a sociedade não existe de forma independente da atividade humana (o erro da reificação), mas ela não é o produto da atividade humana (o erro do voluntarismo). 
O mundo social é, por conseguinte, estruturado, diferençado e em mudança, enfim, histórico. Tal totalidade, afirma Lukács (1979, p. 40), é um complexo de complexos, de complexos, de complexos no qual "todo 'elemento' e toda parte é também (...) um todo; o elemento é sempre um complexo com propriedades concretas, qualitativamente específicas, um complexo de forças e relações diversas que agem em conjunto". Nessa concepção, por exemplo, a educação é um complexo e assim deve ser compreendida e apreendida. Ora, se o mundo social é esse complexo de inúmeros complexos, o que dizer da atividade humana, do agir humano, nessas circunstâncias? Como se articula o agir individual com o conjunto da sociedade?

Diferentemente do mundo inorgânico e orgânico, o ser humano tem que adaptar a natureza às suas necessidades, produzindo e reproduzindo seus meios de existência. É esse agir sobre a natureza e sobre o mundo social que Lukács (1984) chama de trabalho. Por essa razão, de acordo com o autor, todo agir humano tem no trabalho seu protótipo, quer dizer, o trabalho é a primeira relação social, é uma prática exclusiva do ser humano. É o trabalho que faz o ser social emergir do ser natural - orgânico e inorgânico - e assumir sua especificidade social, sempre mais ampla no curso da história. ${ }^{2}$

O momento divisor entre o ser social e o ser natural demarca-se não pela fabricação de produtos, mas pelo papel da consciência, a qual, precisamente aqui, deixa de ser mero epifenômeno da reprodução biológica: o produto é um resultado que no início do processo já existia "na representação do trabalhador", isto é, de modo ideal. Marx (1982, p. 211-212) já afirmava, em $O$ capital, que uma aranha executa operações semelhantes às do tecelão e a abelha supera mais de um arquiteto ao construir sua colméia. Entretanto, o que distingue o pior arquiteto da melhor abelha é que ele figura na mente sua construção antes de transformá-la em realidade. Ou seja, ao final do processo de trabalho, efetiva-se um resultado que já existia antes como prévia ideação na mente do trabalhador. Ele não transforma apenas o material sobre o qual opera; ele imprime o projeto que tinha conscientemente em mira, o qual constitui a lei determinante do seu modo de operar e ao qual tem de subordinar sua vontade.

Somente a espécie humana possui a capacidade de, por intermédio do trabalho, adaptar o ambiente às suas necessidades. Ao contrário do ambiente natural - o das abelhas e das aranhas, que estão presas 
"A teoria tem consequências": indagações sobre o conhecimento no campo da educação

aos limites de adaptabilidade de sua própria espécie -, os seres humanos rompem e transcendem os limites de sua espécie e transformamse, na história, transformando o mundo em que vivem. No mundo social, a história substitui a evolução biológica como elemento central do processo de adaptação humana à realidade circundante. Nesse sentido, pode-se pensar a educação como um continuum, sempre histórico, mediando a abertura de novos campos às ações humanas.

Por ser o trabalho fundamento e modelo geral do agir humano, sua análise revela alguns aspectos característicos de toda práxis. Como afirma Bhaskar (1979, p. 44), a "ação humana é caracterizada pelo notável fenômeno da intencionalidade”. Ou seja, é a capacidade de pôr uma finalidade, de projetar o resultado de uma determinada prática e de rastrear seus resultados que distingue o agir humano do comportamento meramente biológico, fundamentalmente instintivo. A transformação de um resultado ideal (uma mesa previamente pensada, uma aula previamente preparada) num resultado efetivo (uma mesa real ou uma aula, exatamente como planejadas) é a objetivação de um produto ideal, anteriormente pensado.

Nesse processo, amplia-se continuamente a rede de determinações que se tornam cognoscíveis e, por conseguinte, o trabalho alcança patamares cada vez mais variados, expande-se sempre a campos mais largos, sobe de nível tanto em extensão quanto em intensidade. É o recuo das barreiras naturais, de que fala Marx, um processo que acompanha a crescente sociabilidade humana ao longo do tempo. Ademais, se a sociedade antecede a existência dos indivíduos, a práxis significa trabalhar sobre e com determinadas causas materiais (no sentido aristotélico da expressão), estruturas sociais, objetos sociais que estabelecem as condições para as atividades intencionais dos indivíduos, que buscam transformá-los de tal forma a atingir uma finalidade préestabelecida (Medeiros, 2004, f. 8). Lukács (1984, p. 355) assinala que, para alcançar um objetivo concreto, deve ser conhecida a constituição dos objetos, suas relações, prováveis consequências etc. Por isso, afirma: "a práxis está inseparavelmente ligada ao conhecimento; por isso o trabalho (...) é a fonte originária, o modelo geral, também da atividade teórica dos homens".

O outro aspecto distintivo da atividade humana é a escolha entre alternativas. A práxis humana é uma decisão entre alternativas, já 
que todo indivíduo singular, ao colocar uma finalidade em sua ação, deve decidir se a faz ou não, como a faz e em que circunstâncias. Todo ato social, por consequência, surge de uma decisão da consciência humana entre alternativas acerca de finalidades futuras. Ressalte-se, aqui, o caráter social da alternativa, ou seja, é o processo social que determina, delimitando concretamente o espaço das perguntas e respostas possíveis, as alternativas que podem ser realmente transformadas em prática, o que permite inferir que a escolha entre alternativas supóe o caráter aberto do mundo social.

A escolha entre alternativas implica: (1) a possibilidade de escolhas entre várias finalidades possíveis (fazer isto ao invés daquilo); (2) a escolha entre diferentes causas materiais adequadas a tal finalidade (a escolha da madeira adequada para a mesa planejada ou do tema da aula a ser ministrada) e (3) a escolha entre diferentes possibilidades de produzir o resultado pré-estabelecido com as causas materiais selecionadas (fazer uma mesa ao estilo barroco e não uma mesa para computador, construir uma escola em um bairro da cidade ou na zona rural) (Medeiros, 2004, f. 6). Fazer uma mesa surgir da madeira, conforme idealizada, supõe conhecer as propriedades da madeira, das ferramentas empregadas, do ambiente no qual se trabalha e da capacidade humana de trabalhar com aquelas ferramentas sobre a madeira, naquele ambiente. Construir uma escola na cidade ou no meio rural tem implicaçôes sociais que precisam ser conhecidas e avaliadas previamente pelos governantes.

Lukács (1984, p. 25) assevera que não está inscrito na pedra ou na madeira o fato de que com elas se pode construir uma casa. Para que isso aconteça é preciso o poder do pensamento e da vontade humana que ordene materialmente tais propriedades, em uma conexão totalmente nova em seus fundamentos. No entanto, a atividade humana só pode efetivar-se a partir de uma observação atenta das propriedades causais objetivas da realidade - no caso, o conhecimento das características da pedra e da madeira - para atingir a finalidade previamente pensada, sua utilização na construção de uma casa. Da mesma forma, não está inscrito no currículo em si mesmo, por exemplo, o processo de aprendizagem de cada estudante, as condiçóes necessárias para sua efetivação: professores, estudantes, instituição, condições de trabalho, mediação do conhecimento etc. 
"A teoria tem consequências": indagaçôes sobre o conhecimento no campo da educação

Como os indivíduos não existem jamais como sendo singulares, mas como indivíduos em relação a outros indivíduos e em relação às próprias relações, disso decorre que os efeitos de cada ato humano, mesmo que motivado pelas mais profundas razóes individuais, adquirem um significado diferenciado quando analisados em termos do complexo de relaçóes e estruturas sociais. A esse respeito, Bhaskar (1979, p. 51) indica que só se pode perceber a relevância social do agir individual no contexto de uma concepção "relacional" da sociedade: a noção de que a sociedade não é constituída por indivíduos, mas pelas relações entre os indivíduos e pelas relações entre estas relações.

A partir dessa concepção relacional, Bhaskar (1979, p. 51) propóe um sistema de conceitos mediadores que abarcam ambos os aspectos da dualidade da práxis, isto é, um sistema de conceitos que estabeleça o "ponto de contato" entre a ação humana a as estruturas sociais. O sistema mediador é aquele

(...) das posições (lugares, funções, regras, tarefas, deveres, direitos etc.) ocupadas (preenchidas, assumidas, exercidas etc.) pelos indivíduos, e das práticas (atividades etc.) nas quais, em virtude de sua ocupação destas posiçōes (e vice-versa), eles se engajam (...). Ora, tais posições e práticas, se tiverem de ser totalmente individualizadas, somente podem ser executadas relacionalmente.

Falamos aqui de um sistema de relações que permite compreender a ação individual em seu sentido social. Por exemplo, a ação de um professor, como professor, embora seja individualizada, é ação do sujeito que ocupa aquela posição num dado contexto histórico, possuindo assim uma série de determinações sociais particulares. Isso não apaga evidentemente as individualidades (há professores "oradores", há professores que obrigam a leitura de textos, há os que têm facilidade na relação com os alunos, ou não, há os pesquisadores...), mas confere ao agir humano uma dimensão (mais importante, diga-se de passagem) que o individualismo não abrange, e nem poderia abranger (Medeiros, 2004, f. 8). Nas palavras de Bhaskar (1979, p. 44):

(...) as pessoas, em sua atividade consciente, em sua maioria, reproduzem inconscientemente (e ocasionalmente transformam) as estruturas que governam suas atividades substantivas de produção. Dessa maneira, as pessoas não se casam para reproduzir a família nuclear, nem trabalham para 
sustentar a economia capitalista. Contudo, isto é (...) a consequência nãointencional (e resultado inexorável) de, assim como é também uma condição necessária para, sua atividade.

O impacto de atos singulares sobre as estruturas sociais depende da interação de infinitas determinações (das relações com e entre os atos de outros indivíduos). A práxis transformadora é possível, entretanto, como "síntese de inúmeros atos individuais". Medeiros $(2004$, f. 9) assinala que o fato de que tais sínteses se expressem mediante atos de indivíduos singulares (como em Guevara ou Lênin) pode criar a ilusão de que as mudanças resultantes foram consequência direta de sua própria vontade. Este fato indica, ao contrário, que as sínteses de atos individuais não podem ocorrer na ausência dos próprios atos individuais. E se há elemento comum à práxis transformadora e à práxis cotidiana, este elemento é o conhecimento da realidade, mesmo em níveis mais simples. $\mathrm{O}$ conhecimento é importante por permitir escolhas mais adequadas das açôes a serem realizadas no cotidiano, pois somente com o conhecimento dos mecanismos, dos nexos causais, é possível a efetivação da finalidade.

As indicações que fizemos da práxis social - seu caráter intencional; a existência de condiçóes sociais que lhe antecedem; a escolha de alternativas - nos fazem chegar ao ponto que nos é crucial, o do conhecimento. $\mathrm{O}$ ato de conhecer é uma atividade humana e como não conhecemos todas as estruturas, todas as determinações do mundo, os conhecimentos instituem-se, em um primeiro momento, como sistema de crenças ou de interpretações sobre a práxis imediata. Como assinalamos, filosofia e ciência aí se originam, desenvolvem-se como instâncias autônomas para, finalmente, retornarem à práxis imediata e informá-la com novas ou melhores concepções, ou seja, a filosofia e a ciência são refinamentos críticos das concepções obtidas na prática.

Vale lembrar, contudo, que há inúmeros exemplos de teorias e ciências que se mantêm enredadas no domínio da manipulação prática da realidade, sendo incapazes de se libertar dos "preconceitos cotidianos" que permeiam e distorcem a ontologia da imediaticidade. Certas teorias educacionais, por exemplo, esperam que procedimentos e instrumentos de ensino operem praticamente no contexto interior à escola e possibilitem "a compreensão, de um lado, da importância da improvisação na prática pedagógica e, de outro, de um tipo de pesquisa 
"A teoria tem consequências": indagações sobre o conhecimento no campo da educação

vista como resposta imediata e não mediada pela reflexão" (Evangelista, 2001, f. 9).

As epistemologias da prática e suas indicações pragmáticas estão imersas na "religião do cotidiano" (Marx, 1974, p. 900). Assumem que o conhecimento legítimo é o conhecimento fundado e validado na experiência empírica e, dessa forma, são incapazes de compreender as estruturas causais dos fenômenos educacionais. A experiência sensorial é vista como o próprio conhecimento do mundo e o constructo teórico daí recorrente não tem interesse em indagar se a experiência, por si só, pode constituir o mundo de forma adequada (Ávila, 2007, f. 12). Não ultrapassa, assim, as mistificações reais, as categorias falsas ou ilusórias em si mesmas.

São as formas mais sofisticadas de conhecimento e alargamento teórico que permitem a ampliação do escopo da práxis humana, possibilitando um aprofundamento da própria ontologia da vida cotidiana. Como assinala Duayer (2006, p. 117), “o mundo é sempre mediado por nossas idéias, nossa língua, nossa cultura, nosso vocabulário”. Nesse emaranhado de mediações, a descoberta e a correta compreensão das estruturas do mundo são condição básica para a práxis transformadora. Nessas circunstâncias, justamente "por alegar a inexistência de qualquer coisa que não possua proveniência empírica, por negar a realidade das estruturas do mundo e achatar a realidade no domínio dos eventos, o empirismo representa um cerrado bloqueio filosófico-ideológico à simples cogitação da práxis emancipatória” (Medeiros, 2004, f. 31). No domínio social, em particular, em que as estruturas do mundo são abertas e factíveis de transformação, abrir mão de sua compreensão implica naturalizar e eternizar essas mesmas estruturas ou, para ficarmos no campo da educação, implica naturalizar e eternizar as mesmas causas sociais que a impedem de assumir seu papel na práxis emancipatória. Mais preocupante, as estruturas sociais são reproduzidas no pensamento de maneira reificada, fantasiosa ou, ainda, percebidas como um puro e simples enigma.

Para concluir, volto à crítica e à denúncia que anunciei no início da exposição. Por um lado, temos a desqualificação do conhecimento e da teoria que ameaça as ciências sociais e humanas, em particular a educação, com sua atitude indelevelmente passiva e acrítica diante da complexa e intensa dinâmica do dia-a-dia, reduzida a campo de 
percepções sensíveis, da negação do real como composto por intrincado conjunto de estruturas geradoras. Por outro lado, o autoengano das correntes relativistas, a saber, a noção de que o sujeito que conhece cria o universal no pensamento, uma idéia, indica Duayer (2003, p. 14), que traz consigo o absurdo pressuposto de que "o sujeito percebe, classifica, pensa, enfim, sem as categorias do universal e do particular".

Concluo essa exposição afirmando a objetividade e a cognoscibilidade do mundo e que este é muito mais do que as impressões e sensaçóes que dele temos. Se, de acordo com Duayer (2006, p. 130), esta ontologia empírica conforma hoje as "coordenadas ideológicas hegemônicas”, a sua crítica, teórica e prática, só pode ser efetiva com base na reconstrução de uma ontologia realista, "crítica das concepções, das fontes das concepções, das ações fundamentadas sobre as concepções e, finalmente, dos valores e outras condições sociais subentendidos em sua reprodução como concepções correntes" (Medeiros, 2004 , f. 28). Ao contrário das receitas para o futuro, que nada mais fazem do que perenizar o presente, é a análise crítica do existente que pode revelar os possíveis futuros que ele encerra. Neste particular, a educação pode cumprir um importante papel, pois se

(...) os elementos progressistas da educação formal forem bem-sucedidos em redefinir a sua tarefa em um espírito orientado em direção à perspectiva de uma alternativa hegemônica à ordem existente, eles podem dar uma contribuição vital para romper a lógica do capital não só no seu próprio limitado domínio como também na sociedade como um todo. (Mezsáros, 2004, f. 18)

Por isso, concluímos, Thompson e Norris têm razão: de fato, a “teoria tem consequências". A opção está posta: escolhermos uma teoria que contribua para perenizar o presente e administrar o existente, como as várias versões da epistemologia da prática, particularmente na educação, ou uma teoria que proceda à análise crítica do existente, que informe a prática científica consciente de si mesma, pois é o processo histórico-crítico do conhecimento científico que nos ensina (como seres sociais) a capacidade emancipatória da teoria, que nos torna conscientes de nosso papel de educadores que não ignoram que a transmissão do conhecimento e da verdade dos acontecimentos é um instrumento de luta e tem a função de ser mediação na apreensão e 
"A teoria tem consequências": indagaçôes sobre o conhecimento no campo da educação

generalização de conhecimentos sobre a realidade objetiva, sob a perspectiva do domínio sobre a realidade segundo as exigências humanas.

Considerando o que foi dito, quer me parecer, a educação não pode ficar alheia às consequências da teoria.

Recebido em dezembro de 2007 e aprovado em janeiro de 2009.

\section{Notas}

1. Bhaskar enfatiza o caráter explanatório e não-preditivo das ciências sociais. Como o objeto dessas últimas encontra-se em um mundo aberto - e não fechado, como nas conjunções constantes de eventos, das ciências da natureza -, as ciências sociais só podem trabalhar com tendências e não predições exatas.

2. Vale lembrar que Lukács (1981) examina o trabalho em seu aspecto originário - como produtor de valores de uso, como forma "eterna, permanente ao longo das mudanças das formações sociais, do intercâmbio orgânico entre o homem (sociedade) e a natureza". Em outras palavras, o trabalho é analisado por ele como modo de ser do ser humano.

\section{Referências}

ÁVILA, A.B. A pós-graduação em educação física e as tendências na produção de conhecimento: o debate entre realismo e anti-realismo. 2007. 143f. Texto de qualificação (Doutorado) - Programa de Pós-Graduação em Educação, Universidade Federal de Santa Catarina, Florianópolis.

BHASKAR, R. Societies. In: BHASKAR, R. The possibility of naturalism. Brighton: The Harvester, 1979.

BHASKAR, R. Scientific realism and human emancipation. London: Verso, 1986.

BHASKAR, R. Reclaiming reality: a critical introduction to contemporary philosophy. London: Verso, 1993.

BHASKAR, R. A realist theory of science. London: Verso, 1997.

CALLINICOS, A. The resources of critique. Cambridge, UK: Polity, 2006. 
CAMPOS, R.F. A reforma da formação inicial dos professores da educação básica nos anos de 1990: desvelando as tessituras da proposta governamental. 2002. Tese (Doutorado) - Programa de Pós-Graduação em Educação, Universidade Federal de Santa Catarina, Florianópolis.

DUAYER, M. Economia depois do relativismo: crítica ontológica ou ceticismo instrumental? In: CONGRESSO DE ECONOMIA POLÍTICA, 8., 2003, Florianópolis. Anais... Florianópolis, jun. 2003.

DUAYER, M. Anti-realismo e absolutas crenças relativas. Margem Esquerda, São Paulo, v. 8, p. 109-130, 2006.

DUAYER, M.; MORAES, M.C.M. História, estórias: morte do real ou derrota do pensamento. Perspectiva, Florianópolis, v. 16, n. 29, p. 63-74, jan./jul. 1998.

EVANGELISTA, O. A formação de professor nas politicas brasileiras para a educą̧ão nos anos de 1990: algumas questôes sobre a Licenciatura. Florianópolis: PPGE/UfSC, 2001. (Texto não publicado).

GOlDMANN, L. Dialética e cultura. Rio de Janeiro: Paz \& Terra, 1979.

LUKÁCS, G. O trabalho. Trad. de Ivo Tonet. Alagoas: UfA, [s.d.]. 75p. (Título original: LUKÁCS, G. Il Lavoro. In: LUKÁCS, G. Per una ontologia dell'essere sociale. 1984).

LUKÁCS, G. As bases ontológicas do pensamento e da atividade do homem. Temas de Ciências Humanas, São Paulo, v. 4, p. 1-18, 1978.

LUKÁCS, G. Ontologia do ser social: os princípios ontológicos fundamentais de Marx. São Paulo: LECH, 1979.

LUKÁCS, G. Per uma ontologia dell'essere sociale. Roma: Riuniti, 1981. v. $1-2$.

MARX, K. Value, price and profit: an introduction to the theory of capitalism, 1865. Disponível em: <http://ourworld.compuserve.com/ homepages/PZarembka/Marx.htm>. Acesso em: 17 jun. 2007.

MARX, K. O capital. Rio de Janeiro: Civilização Brasileira, 1974. Livro 1, v.1. 
"A teoria tem consequências": indagaçôes sobre o conhecimento no campo da educação

MARX, K. O capital. São Paulo: DIfel, 1982. Livro 1, v. 1.

MARX, K. O capital. São Paulo: Abril Cultural, 1983.

MEDEIROS, J.L. Sete teses sobre o mundo social (e sobre o conhecimento deste mundo). Rio de Janeiro: UFRJ, 2004. (Texto não publicado).

MEZSÁROS, I. A educação para além do capital. Intervenção na abertura no Fórum Mundial de Educação, Porto Alegre, Brasil, 28 jul. 2004. Trad. de T. Brito. Disponível em: <http://resistir.info/>. Acesso em: 20 nov. 2004.

MORAES, M.C.M. Os “pós-ismos” e outras querelas ideológicas. Perspectiva, Florianópolis, v. 14, n. 25, p. 45-60, jan./jun. 1996.

MORAES, M.C.M. Reforma de ensino, modernização administrada. Florianópolis: NUP/CED/UfSC, 2000. (Série Teses).

MORAES, M.C.M. Recuo da teoria: dilemas da pesquisa em educação. Revista Portuguesa de Educação, Lisboa, v. 14, n. 1, p. 7-25, 2001 .

MORAES, M.C.M. (Org.). Iluminismo às avessas: produção de conhecimento e políticas de formação docente. Rio de Janeiro: DP\&A, 2003.

MORAES, M.C.M. Incertezas nas práticas de formação e no conhecimento docente. In: Moreira, A.F.B. et al (Org.). Currículo: pensar, sentir e diferir. Rio de Janeiro: DP\&A, 2004.

MORAES, M.C.M. O renovado conservadorismo da agenda pós-moderna. Cadernos de Pesquisa, São Paulo, v. 34, n. 122, p. 337-357, maio/ago. 2004a.

MORAES, M.C.M.; MÜLLER, R.G. História e experiência: contribuiçôes de E. P. Thompson à pesquisa em educação. Perspectiva, Florianópolis, v. 21, n. 2, p. 329-350, jul./dez. 2003.

NORRIS, C. What's wrong with postmodernism, critical theory and the end of philosophy. Hampstead: Harvester; Wheatsheaf, 1996.

OLIVEIRA-FORMOSINHO, J. A supervisão pedagógica da formação inicial de professores no âmbito de uma comunidade da práctica. 
Infância \& Educação: Investigação e Práticas, Porto, n. 4, p. 42-68, 2002.

PERRENOUD, P. Construir as competências desde a escola. Porto Alegre: Artes Médicas, 1999.

RAUPP, M.D. A produção acadêmica sobre formação de professores de educação infantil: concepções de formação. 2007. 183f. Texto de qualificação (Doutorado) - Programa de Pós-Graduação em Educação da Universidade Federal de Santa Catarina, Florianópolis.

SCHÖN, D. Formar professores como profissionais reflexivos. In: NóvoA, A. Os professores e a sua formação. Lisboa: Dom Quixote, 1997.

SCHÖN, D. El profesional reflexivo: como piensan los profesionales cuando actúan. Barcelona: Paidós, 1998.

SHIROMA, E.O. O eufemismo da profissionalização. In: Moraes, M.C.M. (Org.). O Iluminismo às avessas. Rio de Janeiro: DP\&A, 2003.

TARDIF, M. Saberes profissionais dos professores e conhecimentos universitários: elementos para uma epistemologia da prática profissional dos professores e suas consequências em relação à formação para o magistério. Revista Brasileira de Educação, São Paulo, n. 13, p. 5-24, jan./ abr. 2000 .

THOMPSON, E.P. Debate de Oxford, realizado em dezembro de 1979, um ano após a publicação de The poverty of theory. O debate fez parte da programação do Seminário, sob a coordenação de Raphael Samuel, promovido pelo Ruskin College e pelo grupo "History Workshop". Oxford, 1979. (Informações acessíveis no Ruskin College em fitas cassetes). 